\title{
Risk, Return to Industry, and The Future of Democracy
}

\author{
Lukas Szrot
}

\begin{abstract}
Reflecting on 2020, I consider the possibility of the collapse of the United States, as well as the ways in which it has fallen short of representative and democratic promise. I argue that the spread of conspiratorial reason is symptomatic of the mistrust that has arisen from these failures. Drawing on naturalist, critical theory, and sociology of knowledge accounts of conspiratorial reason, I argue that such thinking is interest-bound, weaponizing mistrust, and is broadly appealing but ultimately disempowering, serving the ends of failed praxis and reification of power. I examine two possible sources of institutionalized mistrust: the "culture wars" thesis which argues that mistrust is iteratively linked to polarization along religious, racial, and cultural lines, and Ulrich Beck's vision of a "return to industry" in which responses to novel hazards are constrained by techno-economic imperatives that politicize knowledge and splinter class loyalties. I emphasize the second explanation without discounting the first, arguing that this approach to hazards, from COVID to institutional discrimination to climate change, is both unsustainable and self-thwarting in terms of building social trust. Then, drawing on Beck as well as scholars from various democratic traditions, I offer possible future visions, including but not limited to avenues toward restoration of social trust in the United States, based on this analysis.
\end{abstract}

I have worked on this paper on and off through 2020. For months I considered, and rejected, multiple possible approaches that followed from the spectacle as I watched the year unfold. When former Minneapolis PD officer Derek Chauvin murdered George Floyd by kneeling on his neck for upwards of eight minutes, causing his death, it was followed by record-breaking international Civil Rights protests, and widespread calls to reform, defund, or even abolish the police. The trial of Chauvin began the week I drafted this paper, and dominated the Minnesota news cycle. Being both a sociologist who recently moved to Minnesota, and a sympathetic human being, I was moved to put these events into context. As I finished this work, over 500,000 U.S.-Americans had died from COVID-19, and over 30 million had been infected. In recent months, heavily-armed militiamen confronted police and stormed federal buildings, assembled to threaten protesters in scattered towns and suburbs, rallied against the largelynonexistent threat "antifa," and worked alongside elected officials to delay Congress' (ordinarily) largely-symbolic role in confirming the next President of the United States.

Is the United States a failed state? For years, I have tried to maintain optimism, or at least composed skepticism, without sinking into the "it can't happen here" complacency shared by so many U.S.-Americans, even in the face of growing apprehension and doubt. The United States is typically referred to as a "representative democratic republic," and as a state, is traditionally expected to hold "the monopoly on the legitimate use of physical force within a given territory" (Weber 1946:78, emphasis in original). To claim the "failure" of this state would mean that these elements are no longer present. I am less interested in diagnosing the failure than in examining how each of these elements have fallen short of their promise, how such failures reflect long-standing and multiple disintegrations in social trust underpinning the events of 2020, as well as how broader historical, cultural, and political-economic elements have 
driven this disintegration.

In the wake of COVID-19 and its human as well as economic consequences, the average U.S.-American is struggling, financially, with tens of millions facing precarity, unemployment, eviction, and homelessness. That the U.S. stands alone among wealthy nations in lacking a public health care infrastructure reflects a long-standing tension between a vocal minority of the U.S. population who hold an ideological suspicion of "government" (see Jouet 2017:157-62) coupled with standing idiosyncrasies of the U.S. electoral system that give outsized power to some minorities (largely white, rural voters who lean Republican) while systematically disenfranchising others (particularly low-income persons of color living in urban areas who lean Democrat). Since the failed coup of January 6, Republican legislatures have introduced scores of bills designed to make voting more difficult in areas densely populated by voters of color, using largely-nonexistent "voter fraud" claims as justification (see Certo 2021). Former President Trump was declared the 45th President after losing the popular vote to contender Hillary Clinton by over two million votes in 2016, whereas in 2020, Joe Biden won the popular vote by over eight million. However, the Electoral College totals for the winners were almost identical (DeSilver 2020). At the legislative level, each state elects two senators, meaning that in the upper chamber of Congress, a state such as Wyoming, with a population of around half a million people, has just as much representation, and power as California, with a population of over 39 million (Riccardi 2020). Some fear that "open rejection of democracy" and denial of 2020 election results has become part of official political platforms given the above trends, coupled with the fact that over a hundred members of Congress voted against certifying 2020 presidential election results (Riccardi 2020). After former President Trump spent his final months in office sowing fear of widespread voter fraud, more than five dozen post-election legal challenges and multiple recounts failed to produce evidence of widespread fraud (Cummings, Garrison, and Sergent 2021). Taken together, these facets of the U.S. electoral system call into question whether it has ever been representative of the will of the majority of its population, while also illustrating its current precarity.

The immediate "why" is simple: lack of trust. Social trust has failed, or is failing, on multiple levels and across multiple fault lines simultaneously. To shift the conversation from the language-game of political science to that of sociology, legitimacy can be thought of as a kind of trust, and no state-no society-long survives without it. Societies live on trust, and die on mistrust. However, trust is not a thing that can be manufactured, nor is it a feeling that can be magically restored once undermined; it is both a necessity among an inherently social species, as well as an ongoing and largely quotidian process rooted in interaction. This was perhaps most clearly articulated in the work of Emile Durkheim (2014), arguing both for the primacy of the social as well as importance of solidarity in coordinating social life. Two important facets emerge from Durkheim's work. The first is his critique of "the social contract" as basis for social trust, including a rejection of the primacy of the self-interested individual in favor of the primacy of altruism and social solidarity as the basis of society. This becomes increasingly evident as societies become more complex and differentiated, paralleling an expansion of legal frameworks alongside the transition toward solidarity rooted in occupational specialization (Durkheim 2014:158-79). Second, the failure in social solidarity and collapse of trust can be traced, then, to a pathological division of labor, which result from political-economic instabilities, class warfare, and poor coordination between specializations (among other possibilities—see Durkheim 2014:277-308).

Durkheim theorizes mistrust as rooted in broader conditions of labor and its relationship to social solidarity. This raises two distinct issues in turn: the first involves whether, and to what extent "external" factors drive this dissolution of solidarity, and if so, where and why those factors arise here and now. The second issue involves how that breakdown of solidarity manifests itself. The first involves the emergence of a novel civilization characterized by global hazards (see Beck 1992, 2015); the second involves the proliferation of conspiratorial reason.1 The second, as I will show, leads back to the first. This paper, therefore, is divided into two broad sections. In the first, I analyze "conspiratorial reason" as diagnosis of social mistrust, bringing multiple perspectives into communication in order to build toward a more precise, comprehensive, and useful definition of "conspiratorial reason." In the second, I bring this "pragmatist account of conspiratorial reason" into dialogue with the cultural, as well as political-economic causes of its appeal and proliferation, with an emphasis on the work of Ulrich Beck. I conclude with some thoughts on possible future directions based on this connection with a focus on the United States. 


\section{Conspiratorial Reason, Power, and Critique}

Conspiratorial reason is by no means a novel phenomenon in the United States, and evidence of its persistence is easy to come by (see Jouet 2017: 63-79; Lavin 2020; Uscinski 2021). Popular and scholarly analyses have often focused on conspiracy theories as evidence of a departure from Enlightenment commitments to reason and science. I refer to this as the naturalist account of conspiratorial reason-that is, it rests on an epistemic commitment to viewing science as the systematization of reason. At the further end of this philosophical continuum, knowledge is essentially what science shows knowledge to be (for a pragmatist critique of this position, see Putnam 1995:3-22). Rationality is wedded to science, and it is departure from this commitment itself, a turn, or return, to a "darker age," that drives conspiratorial reason. In fact, the use of the term "reason" as attached to "conspiratorial" in this context would make the naturalist balk - to be "conspiratorial" is to be "not reasonable." This position is perhaps most eloquently expressed by Carl Sagan (1996) in his magnum opus, published shortly before his death, The Demon-Haunted World:

Avoidable human misery is more often caused not so much by stupidity as by ignorance, particularly our ignorance about ourselves. I worry that, especially as the Millennium edges nearer, pseudoscience and superstition will seem year by year more tempting, the siren song of unreason more sonorous and attractive. Where have we heard it before? Whenever our ethnic or national prejudices are aroused, in times of scarcity, during challenges to national self-esteem or nerve, when we agonize about our diminished cosmic place and purpose, or when fanaticism is bubbling up around us - then, habits of thought familiar from ages past reach for the controls. The candle flame gutters. Its little pool of light trembles. Darkness gathers. The demons begin to stir (26-7, see also Szrot 2015:142).

A quarter of a century later, there is perhaps a prophetic air to it. The naturalist account of conspiratorial reason points to social unrest or times of insecurity as linked to the flourishing of conspiracy theories or rejection of reason in favor of more basic impulses. This account tends to note the role of social unrest and insecurity, but does not in turn interrogate the causal factors driving sociopolitical events-one is left to imagine that they are largely idiographic case studies in historical contingency rather than the manifestation of laws, patterns, or trends (thereby presuming a break between the "hard" science on one hand and the "soft" sciences/humanities on the other). In terms of causality, the naturalist account looks instead to human nature, specifically to the evolutionary fallibility of the human beings and our attendant mental architecture. Exemplifying this is the argument, made popular in evolutionary psychology, that human beings have an inborn tendency to seek patterns, and even false pattern recognition meant survival for our prehistoric ancestors. On average, it is better to anxiously flee a rustling in the tall grass when it is just the wind, than to second-guess the rustling and become a predator's next meal. This tendency manifests itself as a lapse in reason given the prevalence of beliefs in conspiracies and pseudoscience (see, for example, Shermer 2003:32-58).

The naturalist may therefore fall back on a biological explanation to explain the prevalence of conspiratorial reason. What served us well on the savannah leads us astray in the information society. Human beings are ultimately primates, and when angered, afraid, or aroused, differences in beliefs and behaviors reflect our difference of degree, not kind. This is, from the standpoint of an evolutionist, humanist, pragmatist, and social behaviorist 2 like me, undoubtedly the case. However, there is a danger in the naturalist account of tautology of asserting that people are irrational apes because people are irrational apes. And indeed, this can potentially take on the form of secularized "original sin" - an axiomatic belief in the fallibility of human beings. Dewey, among others, has challenged the apparent circularity of this view upheld as an explanation, reflected perhaps most evidently in his debate between himself and theologian Reinhold Niebuhr (see Hook 1995:172-74).3 More importantly, moving beyond this approach allows for another set of popular explanations to be rendered suspect. Drawing on Dewey's (1989) criticisms of "human nature" once more: "Those who wished to justify the exercise of authority over others took a pessimistic view of the constitution of human nature...what passed as psychology was a branch of political doctrine" (29-30).4 It does not seem accidental that protecting hereditary or "natural" social hierarchy and refusing empirical method in certain domains are linked-it represents a kind of "naturalistic mystification" as Mills (1985) described. In this context, searching for a satisfactory explanation of broad failure of trust solely in the fallibility of "human nature" risks providing fodder for a specific kind of cognitive model — and social hierarchy. This is not because the naturalist account is wrong. As a starting-point for an explanation it offers an evolutionary account of where conspiratorial 
reason comes from as well as a partial sociological account of when and why it might be appealing. As will be shown, it also offers important and humbling correctives to the intellectual elitism sometimes wielded in discussions of "conspiracy theory." Building on this means critiquing problematic assumptions about what conspiratorial reason does. That is, an account must also capture the "cash value" of conspiratorial reason, to paraphrase William James (see Capps 2019). The pragmatist is interested in what our ideas about the world do-if conspiratorial reason does not "do" anything that can be theorized, then it does not in fact deserve to be called reason. The practical aim of analyzing conspiratorial reason must reach well beyond the truism that human reason is far from perfect, but living in a society populated by more reasonable people is to be preferred.

There are several pitfalls in any discussion of conspiratorial reason that have ensnared those seeking amore lucid understanding. In terms of the naturalist account, there is the danger of arguing that conspiratorial reason is driven by hucksters and charismatic strongmen who have duped millions of unwitting followers for the purposes of gaining money, power, or fame. This approach is much more common in public forums than among serious scholars of conspiratorial reason, but is nonetheless problematic in its consequences. The corollary being that those who can see the conspiracy "as it really is" are able to elevate themselves at the expense of these presumed dupes. This is itself a form of cultural distinction (see Bourdieu 2003) — a kind of intellectual elitism—that risks preventing more careful consideration of what motivates conspiratorial reason.

At the level of social theory, Weber, via Smith (2013), offers a useful corrective: For Weber, charismatic leaders derive power from the "bottom-up," from followers conferring legitimacy more so than "top-down," through leaders bamboozling unwitting and vulnerable people via some kind of otherworldly gift. This approach "disenchants charisma," opening greater conceptual space to more carefully_and practically_consider the motivations and interests of persons, groups, and institutions implicated in the ongoing unraveling of social trust. It also brings current events into stark relief: the human beings who find conspiratorial reason compelling, and consequentially have supported, and support, flouting democracy and rule of law, are not simply fools or dupes. They are acting on what they take to be in their best interest, based on limited information; they know, and believe in, what they are doing, and are convinced that it is the right thing to do. This re-centers legitimacy as a "bottom-up" phenomenon, and allows one to avoid making the facile claim that many who adhere to conspiratorial reason are simply "dummies" or "dupes" being misled by a strong leader. This is not the only way in which power might enter the explanation, however, as will be shown.

A second pitfall emerges in the context of a critique of critical theory itself. If critical theory is itself "conspiratorial," insofar as it takes aim at making connections that are often missed, passed over in silence, or seem "far-fetched," then perhaps the widespread conspiratorial reason reflects sincere efforts to grapple with the complexity of a world in which a few seem in fact to have outsized power over the many. One approach would parallel Jameson (1988) that views conspiratorial reason as the critical theory of the common person, an attempt to map, better make sense of, and seek critical distance from the repressive, maddening, and incomprehensible system of late capitalism. A related approach, championed by Bruno Latour points to the proliferation of conspiratorial reason as a consequence of critical theory in the university (see Marasco 2016:242).

Implicit in both approaches is intellectual elitism in different clothes-in Jameson's vision, what separates critical theorists from the "common person" is an increase in erudition and perhaps a decrease in desperation. In Latour's critical theory, the spreading beyond the universities that birthed it (itself a dubious claim) bas caused conspiratorial reason. Both visions would give dubious power to both the university, and to the small enclaves of "critical theory" existing precariously within it. With Marasco (2016), what both get right is that conspiratorial reason does in fact live within, and at least share an elective affinity with, critical theory. A second corrective to this approach comes from the naturalist account itself, and is, in my view, one of the great strengths of the approach. Survey data have long reminded social scientists and opinion pollsters of the prevalence of conspiratorial reason, and some of its cousins-paranormal and pseudoscientific claims (Moore 2005; Rose 2020; Szrot 2015:92-8). In a naturalist account, a strong majority of U.S.-Americans holding scientifically improbable beliefs is cause for humility and self-reflection on the sheer depth of fallibility that underpins human cognition and capacity for reason. It is not believing strange 
or unlikely things that makes conspiratorial reason at heart, problematic, as this is quite common. It is not unique to "critical theory" or "common people" (let alone one's ideological adversaries). This again begs the question: what does conspiratorial reason actually do?

Social movements scholarship has long demonstrated that conspiratorial reason, as a means of simultaneously sowing social distrust and providing a sense of order, is a common political tool, particularly among political "outsiders" (see Stewart, Smith, and Denton 2012:285-306). It follows that in practical terms, conspiratorial reason is better understood as taking root insofar as it serves some specific concrete purpose related to personal or group interests - or, at least, to what people take their interests to be. Richard Hofstadter, famously penning The Paranoid Style in American Politics, argues that conspiratorial thinking provides something "far more coherent than the real world, since it leaves no room for mistakes, failures, and ambiguities" (1964:32). This plural approach, wedding the naturalist account to both political aims and social-psychological appeal, means that conspiratorial reason in some regards resembles sociologies of knowledge anchored in standpoints based on the power of those who hold them (Szrot 2015). These, with Mannheim (1936), are variously rendered ideological, insofar as "ruling groups can in their thinking become so intensively interest-bound to a situation that they are simply no longer able to see certain facts which would undermine their sense of domination," or utopian, such that "oppressed groups are intellectually so strongly interested in the destruction and transformation of a given condition of society that they unwittingly see only those elements in the situation which tend to negate it" (40).

Political and social movements which exist outside the halls of power can potentially draw upon their relative powerlessness for myriad aims, weaponizing conspiratorial thinking through narrative in order to personify social evils at once real and perceived. In pragmatic terms, I argue that the appeal of these approaches, whether utopian or ideological in their standpoints, is outmatched by the numerous hazards such approaches pose. Conspiratorial reason isn't "bad" because it hinges on drawing unlikely connections between seemingly unrelated events, let alone because it attempts to interrogate the complexity of power structures. In terms of utopian aims, this is a problem because of the "ineffectual and impatient praxis" (Au 2019:68) that attends a litany of social movement failures, in part a result of rhetorically simplifying the ambiguity, complexity, and ambivalence of the social world and the relationships that inhere within it. Working toward social change with an insufficient, simplistic, or misleading understanding of the problem, well-meaning activism feeds into simplistic "pseudo-realities" (Adorno 1998; Au 2019: 60-3) or increasingly symbolic and ineffectual abstractions in a quest for broader support (Au 2017, 2019). The appeal of conspiratorial reason leads to disempowerment, or at least to distraction.

Conspiratorial reason, used ideologically, has qualitatively different aims. Drawing again on Au (2019) via Adorno's (1994) regression of consciousness, conspiratorial reason in the service of ideology intentionally disempowers: "That is, when we submit to the will of the gods, rather than see society - and its problems - as a network of mediated interactions that we constitute, we sit on our hands and abandon attempts to change reality" (Au 2019: 56-7). There is perhaps an explanation of an immediate social phenomenon that is superficially satisfying, at least from the standpoint of the interests it serves, but the explanation is crafted to draw attention away from, and thereby foreclose upon, broader critical explanation. However, conspiratorial reason in the service of ideology would seem to do far more than this. Illustrating this means briefly revisiting Hofstadter's original formulation of the "paranoid style," as well as Marasco's (2016) critique of it. Hofstadter's formulation was predicated on the practical problems of extremism and failure of moderation. The flattening of motives and rejection of ambiguity served the aforementioned social-psychological purposes, as well as being tied to political aims. What Marsco (2016) via critical theory adds to this, and what is particularly germane to conspiratorial reason used ideologically as described here, is the Freudian conception of conspiratorial reason as:

...a certain idealization of big power. What is more, conspiratorial reason is an idealization of power itself, in which power really is what it says about itself, really is all-powerful, really does have clear and known ends, and really can meet these ends...conspiracy theory is a love affair with power that poses as its critique. Like so many love affairs, it is premised on a fantasy about its beloved. The task of critical theory is to decipher a structure of thinking and feeling, not dismiss or indulge it (Marasco 2016:238). 
Despite its appeal and potency, conspiratorial reason, an effort to weaponize and perpetuate mistrust, is ultimately disempowering when put in the service of either utopia or ideology, leading away from, rather than toward, the more lucid assessment of the world which is a necessary but not sufficient condition of changing it. In its ideological formulation, conspiratorial reason protects power like a desperate lover protecting a fantasy of a beloved; a love affair with power that allows no ambiguity or complexity in human motives, particularly in the motives of "the Other"...this is the seed of the concrete fascism that the Frankfurt School warned about (see Horkheimer and Adorno 2002). What is at stake in accurately assessing what conspiratorial reason does in practical terms is to decipher the interests that it serves and the ends toward which it strives, while keeping at the forefront of such analysis a spirit of humility and self-reflection. I have offered plural motives that drive conspiratorial reason, as well as theorized plural consequences of it, in working toward a means by which to assess the role that conspiratorial reason plays as driver of social mistrust. In doing so, I seek to balance universal human fallibility, dignity (as arising from anti-elitist framings), capacity for freedom (both intellectual and otherwise), and the possibility of false consciousness (Putnam 1994:54-5).

A brief pragmatist interpretation of false consciousness 5 is in order before situating these tendencies toward conspiratorial reason in the current cultural and political-economic landscape. Per Dewey's philosophy of mind, thinking is an inherently social activity which takes the form of a plan or potential course of action which can be selected, or not, based on the environment and ever-changing knowledge and conditions (see Hook 1995:51-73). Blurring the dichotomy between thinking and acting, between subject and object, and between self and society, means that false consciousness arises not merely because a person thinks or acts in ways that are against their interests, or that they incorrectly assess their interests. It is the possibility of consciously committing to courses of action that are themselves self-thwarting, resulting in consequences that both run counter to plans as well as foreclosing on the possibility of future planning. Attempting social change based on hasty conclusions and conspiratorial thinking serves both functions. Utopian sociologies of knowledge which simplify human motivations and social phenomena result in myriad "unintended consequences" which place their adherents in an untenable position regarding praxis; ideological sociologies of knowledge force adherents into the untenable position of consolidating power while seeming to unmask it. I have considered elsewhere that this is the methodological contribution to more effective praxis made by Popper in his apparent critique of the Frankfurt School, even though the debate itself seems to have been a "misfire" (D'Amico 1990; Popper 1961; Szrot 2014). That is, the social, in its ambivalence and complexity coupled with its Durkheimian primacy, invites careful analysis, but such analysis insofar as it affects change itself must not fall into three distinct traps: the ideological trap, in foreclosing on the possibilities of change, often to protect the status of one group at the expense of another; the reformist trap, or becoming dogmatically committed only to gradual reform within existing, potentially flawed or dysfunctional, institutions, perhaps out of fear of "innate" (natural?) human fallibility; the utopian trap, or prioritizing perfection which is unattainable where improvement is possible, leading to the pseudo-realities and unactionable abstractions (Adorno 1998; Au 2019). Overcoming disempowerment and the institutionalized mistrust that led to failure means judiciously avoiding the Scylla of hasty praxis as well as the Charybdis of ideology. It also means confronting the narrative visions that make perpetuation of disempowerment possible, from social theory to popular rhetoric. As noted by Jameson, the "winner-loses" inverted world of theory can have similar paradoxical effects:

What happens is that the more powerful the vision of some increasingly total system or logic...the more powerless the reader comes to feel. Insofar as the theorist wins, therefore, by constructing an increasingly closed and terrifying machine, to that very degree he loses, since the critical capacity of his work is thereby paralyzed, and the impulses of negation and revolt, so to speak of those of social transformation, are increasingly perceived as vain and trivial in the face of the model itself (Jameson 1984: 57).

The totality of a vision regardless of specific content or aims leads logically to its inescapability. The growing potence of a hidden power leads to the growing impotence of those who theorize it. Evoking a global elite or a New World Order or a Deep State or even an erudite and polysyllabic global supervillain serves these functions well, simplifying reality, sowing mistrust, and recruiting collaborators. However, by establishing an enemy so ubiquitous and powerful that resistance is doomed, or steering attention toward a single movement, group, or person who has the power to stay demon's hand, one actively courts one's own disempowerment. 
However, this is only how mistrust is amplified; I have not established why trust should have failed so completely across so many fault lines at the same time. As a sociologist, I posit something external to this vicious cycle which must provide a motivation, or catalyst, otherwise I have not ultimately escaped the potential circularity of the naturalistic account. If I cannot offer something by way of praxis after criticizing failed and hasty praxis, then I have not vindicated this more complex and pluralistic approach to interrogating conspiratorial reason. Therefore, I offer two possible external motives, or drives, for failure of trust, below, and then connect them to what I take to be two tenable future visions or possibilities for escape.

\section{Culture and the Return to Industry}

Mistrust fed through conspiratorial reason can be a potent political tool. It can also be exploited for the purposes of wielding misinformation to manipulate public opinion, a tool used to great effect by the political Right in the U.S. (see Jouet 2017:63-75). However, conspiratorial reason, despite its multifariousness, is in the end a consequence, not a cause, of mistrust. People just do not suddenly, ex nibilo, awaken one morning and decide that a secret cabal of incorrigibly evil people has seized every part of the government and poses a threat to their loved ones, such that they are willing to lay waste to all the institutions that have made life stable and possible in order to stop them. The tools of theorizing conspiratorial reason aid in making sense of the practical aims or ends of various belief structures and the interests to which they are connected. According to an NPR/Ipsos poll published at the end of December 2020, over seven in ten Republican voters, and almost forty percent of U.S.-Americans, believe there is, in fact, a Deep State working to undermine the president. Seventeen percent of U.S.-Americans answered true to the question: "A group of Satan-worshipping elites who run a child sex ring are trying to control our politics and media," and an additional $37 \%$ answered that they do not know for sure (only 47\%, a minority, answered false) (Rose 2020). If, with Durkheim (2014), we take for granted that human beings are social, and we need each other to survive, it follows that mistrust is not a default position, and therefore does not, and cannot, motivate itself.

It also follows that political commitments, particularly in electoral democracies and more individualistic societies, can be seen as a rather superficial reflection of deeper schisms in more durable moral and ontological frames — culture. Political polarization and dysfunction, like mistrust, does not motivate itself. Instead, with Durkheim, (2014),

"Every society is a moral society. In certain respects this feature is even more pronounced in organized societies. Because an individual is never sufficient unto himself, it is from society that he receives all that is needful, just as it is for society that he labors...cooperation also has its intrinsic morality" (178).

A common site of mistrust, as described in the U.S. in terms of moral schism, involves culture. Cultural shifts in the U.S., gaining momentum after the 1960s, drove growing mistrust as people divided increasingly into two culturally distinctive and morally incommensurate camps. Culturally orthodox, or cultural fundamentalist persons appeal to external, transcendent moral authorities such as a god or tradition, interpret holy books literally, and hold socially conservative views; cultural progressives appeal to scientific rationality or subjective experience to shape morality, are secular or interpret religious texts within historical contexts, and hold socially liberal views (see Eve and Harrold 1990; Hunter 1991; Jones 2016:30-3). Jouet (2017) has argued that what is exceptional about the U.S. is captured by facets associated with the culturally fundamentalist or culturally orthodox elements of culture (and that cultural progressives increasingly resemble broad consensus views among other developed nations). He pushes back against this conceptualization of the culture wars by noting the sharp rightward turn of the Republican party in the U.S. of late, as well as the ways in which both religion and U.S. nationalism/exceptionalism have been politicized against a background of religious fundamentalism, anti-intellectualism, and uniquely harsh, punitive views on cultural issues, crime, punishment, and poverty.

In both instances, issues ranging from Civil Rights, abortion, second-wave feminism, and sexual mores to law enforcement practices and decriminalization of vice have driven a wedge between two increasingly divided and vocal camps, each waging ongoing campaigns to gain and hold the cultural center6. I argue that declining trust in government, media, and even education, from this standpoint, can be explained in terms of cultural shifts, and that 
the kinds of conspiratorial reason that are functioning in this context are a reflection of these shifts. The U.S., in particular, is becoming both more secular and more multicultural; mistrust and polarization is a response from the culturally orthodox, particularly whites and Christians, as they lose the cultural center (Jones 2016). Conspiratorial reason which postulates a conspiracy of satanic pedophiles overtaking centers of cultural and political power, however prima facie absurd, is both plausible and emotionally compelling among those who feel anxieties surrounding apparent loss of whiteness and Christianity as central to U.S.-American culture. This implies that culture, as manifested via religion, race, and ethnicity, is the driver of ongoing mistrust. In fact, this conspiracy is a hybrid of two twentiethcentury conspiracies: the "Satanism Scare" of the U.S. during the latter decades of the twentieth century-just as secularization and cultural change began to accelerate (see Richardson, Best, and Bromley 1991); and the "blood libel" anti-Semitic conspiracies that arose in the Middle Ages, which were instrumental in the Nazi power grab in twentieth-century Germany (see Lavin 2020). If conspiratorial reason is, as I have argued, interest-bound, weaponized mistrust, which can be particularly dangerous when functioning ideologically, then these connections point to grim possibilities.

Both sides of the culture wars seek to "capture the moral center"-if every society is a moral society, as Durkheim argues, then this suggests that fundamentally incommensurate moral centers are not likely to thrive within the same society. However, culture, like trust, does not come from nowhere. I have asserted that culture drives aspects of politics; however, the broader political-economic structure in which both take place looms large. I do not commit to economic determinism in all matters (for an incisive pragmatist critique see Dewey 1989:62-81), nor fully discount Rorty's (1998) criticism of how an emphasis on "cultural issues" can and does function ideologically through both media and politics:7

Since economic decisions are their [the super-rich's] prerogative, they will encourage politicians, of both the Left and the Right, to specialize in cultural issues. The aim will be to keep the minds of the proles elsewhere-to keep the bottom 75 percent of Americans and the bottom 95 percent of the world's population busy with ethnic and religious hostilities, and with debates about sexual mores. If the proles can be distracted from their own despair by media-created pseudo-events, including the occasional brief and bloody war, the super-rich will have little to fear (88).

[Mistrust can, and does, arise from cultural shifts and conflicts, but culture can be readily thought of as a survival strategy in turn: religious change, as well as shifts toward cultural progressivism (including greater gender equality, bodily autonomy and more individualistic, self-expressive mores), is driven significantly by changes in existential security based on variations in wealth, health, and education; greater political polarization along religious lines accordingly follows as societies have transitioned from agrarian to "post-industrial" (see Norris and Inglehart 2011). As the development process which gave rise to cultural change has unfolded 8 it has generated increased and increasinglythreatening hazards in the form of side-effects. Drawing on Giddens (2000), the Enlightenment promise, that "the more we are able to rationally understand the world, and ourselves...the more we can shape history for our own purposes" (19) gave rise to this runaway world, in which "science and technology are inevitably involved...but they have also contributed to creating [these risks] in the first place" (21). Burning fossil fuels has led to climate change; the spread of pandemics such as COVID-19 is facilitated by an increasingly mobile and globally-interconnected civilization; racial injustice in the U.S. as it exists today is in part a consequence of urbanization, coupled with an ongoing legacy of geographic segregation and environmental injustice enforced deliberately through politicaleconomic mechanisms (see Bullard 1994; Mohai, Pellow, and Roberts 2009; Rothstein 2017).

These hazards are real — they exist independently of what human beings think of them (see Szrot 2021:3). However, the hazards posed to human beings, by climate change, as well as pandemics, industrialization and urbanization, are not inevitable in their extent and severity. They are shaped by societal responses to risk-how, and to what extent, societies adapt to a changing environment, albeit an environment irrevocably changed by the consequences of human activity. The goal is to come to terms with the metamorphosis, or Die Verwandlung, as Beck (2015) referred to it. There is, accordingly, not a single approach to coming-to-terms, but several. I argue that social trust, or lack thereof, is ultimately a direct consequence of the social and economic approaches favored by the U.S. in coming to terms with hazards. 
In Risk Society, Beck offered three possible visions in coming to terms with the novel hazards which are simultaneously created by, and imperil, societies in a new era of modernity. The first, which Beck (1992) deemed most likely for most societies in most circumstances, he termed "back to industry" (223-28). This approach, looming large in the U.S., involves a "doubling-down" of the paradigm of technical progress and industrial capitalism, with decisions increasingly made first and foremost based on the perceived needs of the economy, and other concerns (including everything from science to employment) expected to be addressed within this framework. Hazards are secondary or tertiary concerns; economic growth, it is presumed, can be relied on to eventually benefit all. An ideology of "rugged individualism" — or more accurately ragged individualism (Dewey 1999:5) — serves as ideological cover, as mystification, for the continued operation of techno-economic logics. In an era of widespread and unprecedented risks, whose impacts are directly shaped by human decision-making, this approach breeds and accelerates mistrust. In U.S. cities, decades of racial oppression erupt in mass demonstrations again and again, capturing widespread public and media attention, but institutional remedies are token or sluggish at best-and brutally repressive at worst. Environmental and public health measures from the most modest steps to mitigate climate change, to wearing a mask to protect others from COVID-19, become fraught imaginaries of power and position, symbolic threats to a machine which must be kept running at all costs.

Per Beck (1992): "As side effects the risks fall under the responsibility of politics and not business. That is to say, business is not responsible for something it causes, and politics is responsible for something over which it has no control" (227). Decades of massive corporate spending was involved in preventing the U.S. public from learning of, and mounting effective regulatory responses to, hazards posed by everything from cigarettes and asbestos to carbon monoxide and climate change. "Merchandising doubt," or selling uncertainty surrounding environmental and public health hazards to prevent regulatory reform, is an ongoing historical travesty that fits comfortably into this paradigm (see Mooney 2005; Oreskes and Conway 2010). That this is accelerated and strengthened by conspiratorial reason and amplified through cultural fears, is evident. U.S.-Americans have had decades to interact with and grow accustomed to the weaponization of mistrust surrounding the reality of, and risk posed by, environmental and public health hazards. That refusing to wear masks became a political statement may be unsurprising for this reason alone. However, the political-economic path on which the U.S. has doggedly committed itself in the face of Beck's (1992) "risk society," of a world faced by increased hazards produced and perpetuated by the very human activity on which such a society comes to depend, structures decision making and securely institutionalizes this mistrust. It is not merely that risk becomes politicized, as Beck's work clarifies. It is that this approach to risk takes for granted that some will win and some will lose. When a highly-contagious and potentially-deadly pandemic strikes a society structured around economic growth and technical progress above all, the results, through the lens of sociology of risk, are tragically predictable:

Resentment fractures societies and undermines trust. Stay-at-home orders became casualties of the "culture wars" precisely because people like me, a middle-class academic, can and do support these efforts while working from home, while "essential workers" face daily risk, and panic among the jobless rises as bills come due. No one is immune to risk for long. Businesspersons squabble with lawmakers, and each other, because of what they stand to gain-or lose-with policy changes. Civil unrest breaks out, placing larger populations at greater risk of infection. Risk fractures old political loyalties and undermines civic trust, "trickling up" to eventually make everyone vulnerable (Szrot 2020).

Beck (1992), writing as a German, goes further in articulating where this vision might ultimately lead:

Perhaps the rejection of 'politics' will then tend to affect not just individual representatives and parties, but the system of democratic rules as a whole. The old coalition between insecurity and radicalism would be revived. The call for political leadership would once again resound ominously. The longing for a 'strong hand' would grow to exactly the degree as people see the world crumbling around them. The hunger for order and reliability would revive the spectres of the past. The side effects of a politics that ignores side effects would threaten to destroy politics itself. Ultimately, it could not be ruled out that the still undigested past [of Germany (tr.)] might become a 


\section{possible developmental option for the future although in a different form (228).}

Mere weeks after the first major shutdowns, the U.S. economy seemed to grind to a halt. As months passed, and distribution of financial aid was lopsided and botched where it happened at all, economic losses pressured small business owners to demand to reopen or defy state regulations even in the face of possible illness or death for business owners, staff, customers, and families. Behind the appearance of "no other choice," resisting or ignoring health guidelines and protocols became a symbolic, ideological defense of a culture guided by this political-economic approach to hazards, and compelled into existence by systemic failure of hazard-response capacity. Public health officials advised staying at home in-between commercials for tourism, dining, and spending holidays with family. Ideologues anxious to keep the machine running, and appease donors and constituents who suffered economically from any lag in growth, ignored or openly challenged experts and even used conspiratorial thinking to undermine the dissemination of scientific knowledge and public trust. Even as COVID-19 may be defeated by vaccination, addressing racial injustice has gone mainstream, and climate change is being taken seriously, the social mechanisms necessary to forward such efforts may have been fatally compromised. At the same time, the proliferation of conspiratorial reason is a predictable consequence based on the model posited here: a toxic stew of cultural polarization, existential insecurity, and multiple fault lines bred and weaponized mistrust, culminating in an attempted coup d'etat on January 6, 2021.

Despite civil unrest and chaos driven by baseless claims of widespread voter fraud, this year, 2021, will see a U.S. Congressional majority, and a president, who are Democrats. This likely signifies a different approach to hazards than the current dominant paradigm. A progressive movement which claims science as part of its political platform offers the possibility that "the auxiliary and alternative governments of techno-economic sub-politics-science and research_could be brought under parliamentary responsibility" (Beck 1992:229). Rhetoric surrounding "listening to the scientists" and "listening to experts" in addressing hazards abounds in the current incarnation of the Democratic Party. Trust in science has effectively become a partisan political stance, with a long history (see Gauchat 2012; Jouet 2017). Beck (1992) stressed that this will either result in increased bureaucratic obstacles to technical and scientific progress, or it will result in the expansion of the welfare state to combat hazards as it has been expanded to combat social ills such as poverty in the past (229).

Rather than the occurrences as described in the first approach, the one most closely aligned to the U.S. as it exists at present, speculations can be offered. If the U.S. had had universal health care, universal basic income, substantive efforts toward redressing racial injustice, and more robust worker protections in place prior to the spread of COVID-19, precarity would likely have been at least partially mitigated. Perhaps, rather than a state trying to regain legitimacy in the wake of a mercurial strongman, mendacious political elites, partisan bickering, cultural fracture, a coup attempt, and a haphazard response to the pandemic, the U.S. and its citizens would have better weathered these trials. This seems like the vision that Democrats, in their more moderate and progressive variations, are embracing, and promoting to the public.

Some or all of these reforms may be necessary to stabilize and rebuild; however, the "welfare-state" approach, championed to degrees by moderate and center-left reformers as well as progressives, involves large-scale expansion of state bureaucracy, likely over a relatively short period of time. The dangers of bureaucracy, as an institutional system cursed by its own impersonal efficiency to become both durable and undemocratic, were well described by Weber (1946a). In particular, this vision, whatever its potential benefits, weds science and technology to the state in the service of combatting global hazards. Together, these tendencies suggest how this approach will be ideologically imperiled in the present U.S. context. "Certain progressive policy measures undoubtedly make it easier to combat global hazards, but they are costly and empower armies of civil servants and expert specialists who are themselves notoriously appointed rather than elected" (Szrot 2020). Mistrust around a "deep state" has been institutionalized in the U.S. among Republicans, along with a resurgence of anxieties surrounding "socialism" and "communism." Neither ideology has ever actually found broad support in the U.S., especially if one accurately views U.S. progressives as social democrats rather than "democratic socialists." However, the spread of these terms reflects conspiratorial reason which holds at its heart, ideological resistance to "government" with deep roots in the past, flourishing 
during the last decade of the Cold War, and nurtured through the neoliberalism that took root during the Reagan Administration. Misgivings about bureaucracy and state expansion in these regards may find little empirical support (see Jouet 2017:143-67); current social democracies appear to function as well as, or better than, the U.S. in terms of securing the well-being of citizens, and fears that regulating markets and progressive taxation would lead to a loss of personal freedom a la Hayek (1994) seem increasingly unfounded.

However, because the cause of failure has been diagnosed here as systemic loss of trust, accelerated through both conspiratorial reason and long-standing cultural conflict, it will be extremely difficult to rebuild society along these political and economic lines given a society which has internalized decades of deep and widespread mistrust toward these approaches. "Trust the scientists" may be a reassuring motto for both current scholars and current Democrats in response to fears of an anti-intellectual populism, but this vision and approach, in the end, does not necessarily translate to higher trust in science. In fact, poorer and more religious countries enjoy somewhat higher levels of trust in science than wealthier and more secular ones (see Norris and Inglehart 2011:68). Additionally, social research has shown that U.S. resistance to science manifests along moral, not epistemic, lines, and this resistance has increased among U.S. Republicans and conservative Protestants over time (Evans 2013; Gauchat 2012; Mooney 2005), placing this approach in profound tension with broader centrist appeals for unity and depolarization and showing how this approach may, at least in the near-term, lead to greater polarization along existing cultural fault lines.

\section{Conclusion: Politics Beyond the Political}

What ineffectual praxis this would make for if I were to end there. I have told a gloomy story about a state at the edge failure, widespread mistrust expressed as conspiratorial reason, nurtured through cultural polarization which is fed, in turn, by a stubborn "return to industry" approach to hazards. In this, I have also briefly visited the fraught political efforts to return from this through the bureaucratic planning and state intervention that appear likely in the coming years. Perhaps the spiral of mistrust can be halted and trust restored through well-intentioned policy measures and expansion of the welfare state. It is, as they say, worth a shot. However, that would presume genuine common ground, coupled with a widespread will and desire to remain together. Maybe it is too late for that. If we do not, and there are good reasons to think this is the case, then failure will lead to social collapse. If, with Durkheim, every society is a moral society, and moral common ground cannot be found or shared, then it seems difficult to imagine how things will play out without a degree of pessimism - at least for some. Perhaps the culture wars will ebb in the face of secularization and the cosmopolitan, cultural progressives will claim the cultural center. However, the fault lines exposed by ham-handed U.S. responses to twenty-first century hazards such as COVID-19 are both multiple and geographically porous: bourgeoisie versus proletariat, as well as religious versus secular, college-grad versus school of hard knocks, Boomer versus Millennial, pro-life versus pro-choice, urban versus rural, white-nationalist versus multicultural, Left versus Right, Texans versus Californians, and so on. Increased violence is likely in any case, scattered but ongoing in the form of civil unrest or incidents of "terrorism" that seem isolated but become more clearly connected to specific ideologies and conspiratorial reason. That white nationalist violence has claimed the most casualties in the U.S. among non-state violence (see Bergengruen and Hennigan 2019) fits tragically well with cultural polarization and conspiratorial reason as weaponized mistrust, deployed ideologically. Barring a successful authoritarian takeover and the resulting suppression of opposition, even in a case of state collapse, there are likely too many divides for anyone to get a lasting upper hand, but such an environment would quickly become a laboratory for all manner of illiberal governance to take hold. Historically, state collapse, though it seems almost unthinkable here and now, has been a regular feature across civilizations, and is often atrocious even when ranked among human atrocities (see White 2012).

It remains possible that authority and legitimacy may devolve to more local spaces. Both staunch critics of the kind of radical, humanistic, global democracy posited by theorists from Dewey to Beck (more on this in a moment, see Lippman 1965), and champions of a conservative, communitarian populism (see Lasch 1995) have acknowledged that democratic norms may function better in smaller spaces. The state as is understood today is a historical newcomer; something more like the city-state, tribe, or band has been more commonplace, historically. A future of smaller and more local "city-state" enclaves, with or without some kind of intercontinental connection facilitated by ongoing 
advances in communication, farming, and manufacturing technologies, remains a possibility (Stucki and Tran 2019). Another possibility would involve communal living centered around farming, scaling back technology, and egalitarian, anarcho-syndicalist governance, such as the Catholic Worker movement (see Stock 2009, 2015; Stock and Szrot 2020).

However, if mutual mistrust reigns, then devolving authority or alternatives to the nation-state will be insufficient to prevent unrest from continuing. Whether or not failure leads to collapse, some version of a multifront internal conflict is already underway, between some combination of independent militias, activist groups and social movements, ideologues, and state actors including police, military, and other security agencies, and "hired guns." Foreign competitor states, and businesspeople looking to enrich themselves and extend their interests, may keep the money, and blood, flowing. For many people, life will go on as normal (if we can be said to be living through anything fitting that description), at least for a time. That may sound far-fetched, but the first signs of this have already taken place. Additionally, experts have shown that this kind of conflict is increasingly the norm throughout the world (see Miranova 2018).

The alternative is learning to trust one another and our institutions again, and for those institutions to warrant such trust, in that they can respond effectively to future hazards - a simple statement that belies a fantastically complex undertaking. To do so means institutions that are not locked into a "return to industry," taking for granted that pitting human beings against one another as "winners" and "losers" is mandatory. This does not mean an end to competition or self-expression, let alone a defense of some kind of bureaucratized planning. Instead, it points to a need for more democracy, when and where it can be manifested, from politics to parenting and from educators to economies, a position shared by many of the scholars and theorists mentioned throughout this work. Democracy begins at home; justice begins at the interpersonal level. In fact, Beckian thought is shot through with erudite optimism, challenging the idea of methodological nationalism if not the notion of a nation-state itself as a central unit of measure for politics, seeking a cosmopolitization that supplants the Western, liberal elitism of Kantian, Enlightenment cosmopolitanism (see Beck 2011). This approach involves apprehending the kinds of hazards that are likely to derail democratic governance and reverse trends in human freedom and wellbeing, of which COVID-19 represents a harrowing example, but is hardly the first or the last hazard to fit such a definition. Such work is likely to be facilitated by the new communication technologies available at present: however, the Internet and social media have thus far perhaps done more harm than good, fostering capitalist oligopoly, consumerism, the spread of misinformation, and increased state surveillance. A more authentically democratic technological framework yet awaits the legal, educational, and interpersonal frameworks, knowledges, and skills which remain beyond the edge of the horizon. Flickers of its possibilities occur here and there and can be tended by self-reflective publics or snuffed out by intolerance for ambiguity and infatuation with power.

In rejection of methodological nationalism, I should want to hold out a hope shared by the U.S.-American pragmatist tradition, that there is both conceptual room, and perhaps a necessity, for patriotism and national pride on the Left. With Rorty (1998) I wish to reject the "principled, theorized, philosophical hopelessness" (37) that has become fashionable in some parts of the Left. To do this work is to directly confront the brute fact that U.S. history includes a litany of unforgivable things. Drawing on Dewey, via Rorty, if one commits an act that one ought to rather die than commit, a truly unforgivable act, but does not die in so doing, there are but three ways forward. "At that point, one's choices are suicide, a life of bottomless self-disgust, and an attempt to live so as never to do such a thing again. Dewey recommends the third choice" (Rorty 1998:33). Whatever the future, this is the choice of the U.S. and its denizens for the future of this country. I hold out hope that the third choice will ultimately be chosen, that the work of living up to the radical promise of the Declaration of Independence, that all person are created equal, will be again be undertaken with stern sincerity, that the future, whatever political form it takes, will look back at the present and declare emphatically: never again. 


\section{Endnotes}

1. After considering the use of "conspiracy theory" and "conspiracy story" or even "narrative," and in the wake of numerous conversations with self-styled "conspiracy analysts" over the past year, I have adopted this term based on the work of Robin Marasco (2016) for the sake of clarity, and to avoid the patrimonial and elitist connotations linked to "conspiracy theory" as a pejorative often wielded by intellectual elites.

2. Drawing on the social behaviorism of George Herbert Mead, human beings are shaped by their interactions with one another over time; it could be argued that society, at its most reductionist, is the sum result of these ongoing interactions and the symbolic meanings attached to them (Mead 1967). Through interaction, habitus develops; a durable collection of habits of mind and embodied skills which come to be second-nature and largely operate unconsciously. Out of habitus, culture, and cultural distinction, develops (see Bourdieu 1993, 2002). Both trust, and mistrust, of institutions is interactional and cultural; it arises, and changes, over time as a result of human beings interacting with one another, and becomes durable through repeated experiences and the symbolic meanings attached to those experiences. Trust, or mistrust, spreads and strengthens over time; the same everyday social-psychological mechanisms that make society possible and durable can also result in a process of ongoing unraveling that is difficult to arrest. Adequately exploring these cultural and interactional tendencies within the erosion of social trust is beyond the scope of this paper, as it would require greater engagement between the biological and social sciences than currently exists, among other things..

3. To clarify, I do, in fact, believe there is such a thing as human nature, which is connected to our biological inheritance and is irreducibly fallible. I have also argued elsewhere for an ontological position which takes for granted that world that is "broken" or irreducibly flawed actually facilitates the possibility of justice (Stock and Szrot 2020:98-100). My goal in this context, however, is to emphasize how the idea of human nature has been, and can be, used ideologically, foreclosing on rather than facilitating more substantive and actionable explanations for conspiratorial reason and the breakdown of social trust.
4. I am reminded of Aristotle, titan of Western philosophy, who both famously argued that slavery is justified, took for granted and explicitly argued for the natural inferiority of some human beings, and in doing so framed the "manual labor" of empirical, scientific work as beneath him (see Weinberg 1992; Sagan 2013; Szrot 2016). His thinking process was not "handed down to him" by some person or group in power; he was famously original in much of his thinking, including challenging the work of his own mentor, Plato. And he was not foolish or a "dupe" by any standard. His thinking process was interest-laden insofar as it reflected a commitment to both the ideology of his time and social-psychologically appealing insofar as it extolled the kind of intellectual work in which he engaged. I am not directly comparing friends and relatives who post dubiously-credible news articles on social media to Aristotle. I am arguing for a similarity in thought process, conditioned by perceived interest and standpoint, which simplifies human motives and serves inevitably to disempower. Not only did Aristotle defend the inherent inequity of human beings; he was unable to see the value of a more directly empirical method in addressing the scores of questions he spent his life pondering.

5. I am aware by using this term in this rather cursory context that I may myself be accused of a kind of simplification, given the vastness of work in the Marxian tradition that addresses this concept. My focus here is on both keeping open the possibility of false consciousness, so as to maintain the possibility of a depth model in thought, action, and social relations of the kind alluded to by Jameson (1985) while also holding that such a model is compatible with the pragmatist tradition in the regards spelled out here.

6. Jouet rejects the "both-sides-ism" of this conceptualization of the culture wars, and Jones focuses on the decline of hegemonic whiteness and Christianity as a driver. Eve and Harrold frame their work in terms of education, particularly the cultural (not scientific) controversy over creationism and evolution in U.S. schools. Hunter's conception of the culture wars is probably the most commonly cited in popular media, despite Jouet's work which argues rather compellingly for the problematic nature of the "both-sides-ism" of this definition of the problem, and also offers a deeper 
historical perspective through which to understand the "exceptionalism" of the U.S. cultural and political right.

7. I introduce this quotation with some hesitation; it reflects, to a degree, the simplistic and intellectually elitist efforts I have elsewhere criticized, and tried to avoid. It is an effort to argue, from an enlightened vantage-point, that the mistrust is being deliberately fueled by the powerful and the "proles" are being duped. However, the thrust of Rorty's argument here seems compelling-that mistrust can be weaponized, and that social change can be, and is, arrested, by shifting attention away from the social and economic conditions that underpin precarity. It is to these conditions that I draw attention here, as fundamental drivers of mistrust, and therefore failure.

8. A process that is, in turn, variously called globalization and development, which is fraught, multifarious, and at once robust and fragile (Blumberg and Cohn 2016)

\section{References}

Adorno, Theodor. 1994. The Stars Down to Earth and Other Essays on the Irrational in Culture. London: Routledge.

Adorno, Theodor. 1998. Critical Models: Interventions and Catchwords. Translated by H. Pickford. New York: Columbia University Press.

Au, Anson. 2017. "Reconceptualizing Social Movements and Power: Towards a Social Ecological Approach." The Sociological Quarterly 58(3): 519-45.

Au, Anson. 2019. "Re-examining Adorno on the Regression of Consciousness and Democracy: Towards Social Transformation." Social Thought and Research 35: 53-78.

Beck, Ulrich. 2011. "Cosmopolitanism as Imagined Communities of Risk." American Behavioral Scientist, 55(10):1346-61.

Beck, Ulrich. 2015. "Emancipatory Catastrophism: What Does It Mean to Climate Change and Risk Society." Current Sociology, 63(1): 75-88.

Bergengruen, Vera and W.J. Hennigan. 2019. “'We're Being Eaten From Within.' Why America is Losing the Battle Against White Nationalist Terrorism." Time, August 8 https://time.com/5647304/ white-nationalist-terrorism-united-states/

Blumberg, Rae Lesser and Samuel Cohn, eds. 2016. Development in Crisis: Threats to Human Well-Being in the Global South and Global North. New York: Routledge.
Bourdieu, Pierre. 1993. The Field of Cultural Production. Edited and Introduced by Randal Johnson. Columbia: Columbia University Press.

Bourdieu, Pierre. 2002. Distinction: A Social Critique of the Judgement of Taste. Translated by Richard Nice. Cambridge: Harvard University Press.

Bullard, Robert Doyle. 1994. Unequal Protection: Environmental Justice and Communities of Color. San Francisco: Sierra Club Books.

Capps, John. 2019. “The Pragmatic Theory of Truth.” In The Stanford Encyclopedia of Philosophy, March 21 https://plato.stanford.edu/entries/truth-pragmatic/

Certo, Peter. 2021. "We May Be One Election from Permanent Minority Rule.” In These Times, March 8. https://inthesetimes.com/article/democrats-filibuster-joe-manchin-permanent-minority-rule

Cummings, William, Joey Garrison, and Jim Sergent. 2021. "By the Numbers: President Donald Trump's Efforts to Overturn the Election." USA Today January 6 https://www.usatoday.com/in-depth/news/politics/ elections/2021/01/06/trumps-failed-efforts-overturnelection-numbers/4130307001/

D’Amico. 1990. "Karl Popper and the Frankfurt School." Telos 86:33-48.

DeSilver, Drew. 2020. “ Biden’s Victory Another Example of how Electoral College Wins are Bigger Than Popular Vote Ones." Pew Research Center December 11 https://www.pewresearch.org/facttank/2020/12/11/bidens-victory-another-example- 
of-how-electoral-college-wins-are-bigger-than-popular-vote-ones/

Dewey, John. 1989. Freedom and Culture. Amherst: Prometheus Books.

Dewey, John. 1999. Individualism Old and New. Amherst: Prometheus Books.

Durkheim, Emile. 2014. The Division of Labor in Society, Edited and with an Introduction by Steven Lukes. New York: Basic Books.

Evans, John H. 2013. “The Growing Social and Moral Conflict between Conservative Protestantism and Science." Journal for the Scientific Study of Religion, 52(2)368-85.

Eve, Raymond A. and Francis B. Harrold. 1990. The Creationist Movement in Modern America. Boston: Twayne Publishers.

Gauchat, Gordon. 2012. "Politicization of Science in the Public Sphere: A Study of Public Trust in the United States, 1974 to 2010.” American Sociological Review, $77(2): 167-87$.

Giddens, Anthony. 2000. Runaway World: How Globalization is Reshaping our Lives. New York: Routledge.

Hayek, Friedrich A. 1994. The Road to Serfdom. Chicago: University of Chicago Press.

Hofstadter, Richard. 1964. The Paranoid Style in American Politics and Other Writings. New York: Alfred Knopf.

Hook, Sidney. 1995. John Dewey: An Intellectual Portrait. Introduced by Richard Rorty. Amherst: Prometheus Books.

Horkheimer, Max and Theodor W. Adorno. 2002. "Elements of Anti-Semitism: Limits of Enlightenment." In Dialectic of Enlightenment: Philosophical Fragments. Translated by Edmund Jephcott. Palo Alto, CA: Stanford University Press.

Hunter, James Davison. 1991. Culture Wars: the Struggle to Define America. New York: Basic Books.
Jameson, Fredric. 1984. "Postmodernism, or the Logic of Late Capitalism," New Left Review, 146(July/ August):53-92.

Jameson, Fredric. 1988. “Cognitive Mapping." In Marxism and the Interpretation of Culture, Edited by Cary Nelson and Lawrence Grossberg. Champaign, IL: University of Illinois Press, pp. 347-57.

Jones, Robert P. 2016. The End of White Christian America. New York: Simon \& Schuster.

Jouet, Mugambi. 2017. Exceptional America: What Divides Americans from the World and from Each Other. Oakland, CA: University of California Press.

Lasch, Christopher. 1995. The Revolt of the Elites and the Betrayal of Democracy. New York: W.W. Norton \& Company.

Lavin, Talia. 2020. "QAnon, Blood Libel, and the Satanic Panic." The New Republic, September 29. https://newrepublic.com/article/159529/ qanon-blood-libel-satanic-panic

Lippman, Walter. 1965. Public Opinion. New York: Free Press.

Mannheim, Karl. 1936. Ideology and Utopia. New York, NY: Harcourt, Brace \& World, Inc.

Marsco, Robyn. 2016. "Toward a Critique of Conspiratorial Reason.” Constellations 23(2): 236-43.

Mead, George Herbert. 1967. Mind, Self, and Society from the Standpoint of a Social Behaviorist, Volume I. Edited and with an Introduction by Charles W. Morris. Chicago: The University of Chicago Press.

Mills, Charles W. 1985. "Marxism and Naturalistic Mystification.” Science \& Society 49(4): 472-83.

Miranova, Vera. 2018. From Freedom Fighters to Jihadists: Human Resources of Non-State Armed Groups. New York: Oxford University Press.

Mohai, Paul, David Pellow, and J. Timmons Roberts. 2009. "Environmental Justice." Annual Review of Environment and Resources 34: 405-30. 
Mooney, Chris. 2005. The Republican War on Science. New York: Basic Books.

Moore, David W. June 16, 2005. "Three in four Americans believe in Paranormal." Gallup News Servicehttp://www.gallup.com/poll/16915/ three-four-americans-believe-paranormal.aspx

Norris, Pippa and Ronald Inglehart. 2011. Sacred and Secular: Religion and Politics Worldwide, Second Edition. New York: Cambridge University Press.

Oreskes, Naomi and Erik M. Conway. 2010. Merchants of Doubt: How a Handful of Scientists Obscured the Truth on Everything from Tobacco Smoke to Global Warming. New York: Bloomsbury Press.

Popper, Karl R. 1961. The Poverty of Historicism. London: Routledge \& Kegan Paul.

Putnam, Hilary. 1995. The Many Faces of Realism. LaSalle: Open Court.

Riccardi, Nicholas. 2020. “Democrats Keep Winning the Popular Vote. That Worries Them." AP November 13 https://apnews.com/article/democrats-popular-vote-win-d6331f7e8b51d52582bb2d60e2a007ec

Richardson, James T., Joel Best, and David G. Bromley. 1991. The Satanism Scare. New York: Aldine de Gruyter.

Rorty, Richard. 1998. Achieving Our Country. Cambridge, MA: Harvard University Press.

Rose, Joel. 2020. “Even if It’s 'Bonkers', Poll Finds Many Believe QAnon and Other Conspiracy Theories." NPRNews, December 30. https://www.npr. org/2020/12/30/951095644/even-if-its-bonkers-pollfinds-many-believe-qanon-and-other-conspiracy-theories

Rothstein, Richard. 2017. The Color of Law: A Forgotten History of How Our Government Segregated America. New York: Liveright.

Sagan, Carl. 1996. The Demon-Haunted World: Science as a Candle in the Dark. New York: Ballantine Books.

Sagan, Carl. 2013. Cosmos. New York: Ballantine Books Trade Paperbacks.
Shermer, Michael. 2003. How We Believe: Science, Skepticism, and the Search for God. New York: Henry Holt and Company.

Smith, David Norman. 2013. "Charisma Disenchanted: Max Weber and His Critics." Current Perspectives in Social Theory 31:3-74.

Stewart, Charles J., Craig Allen Smith, and Robert E. Denton, Jr. 2012. Persuasion and Social Movements, Sixth Edition. Long Grove: Waveland Press, Inc.

Stock, Paul V. 2009. The Original Green Revolution: The Catholic Worker Farms and Environmental Morality. Colorado State University, ProQuest Dissertations Publishing 3374623.

Stock, Paul V. 2015. "Contradictions in Hope and Care: Technological Utopianism, Biosphere II and the Catholic Worker Farms." Food Utopias: Reimagining Citizenship, Ethics, and Community. Edited by Paul Stock, Michael Carolan, and Christopher Rosin, pp. 171-94.

Stock, Paul V. and Lukas Szrot. 2020. “Justice." In Routledge Handbook of Sustainable and Regenerative Food Systems. Edited by Jessica Duncan, Michael Carolan, and Johannes S.C. Wiskerke. New York: Routledge, pp. 98-112.Stucki, Max and Trey Tran. 2019. "City States-The Wave of the Future?" Futures Platform, November 5. https://www.futuresplatform. $\mathrm{com} / \mathrm{blog} /$ city-states-wave-future

Szrot, Lukas. 2014. "Popper, Adorno, and the Methodology Dispute." Telos, November 25. http://www.telospress.com/ popper-adorno-and-the-methodology-dispute/

Szrot, Lukas. 2015. The Idols of Modernity: The Humanity of Science and the Science of Humanity. ProQuest Dissertations \& Theses, University of Texas at Arlington, https://rc.library.uta.edu/ uta-ir/bitstream/handle/10106/25014/Szrot_ uta_2502M_13038.pdf ?sequence $=18$ is Allowed $=y$

Szrot, Lukas. 2016. "Evaluating Enlightenment: Progressive Critiques of Rationalization and Ecology." Telos, February 22 http://www.telospress.com/evaluating-enlightenment-progressive-critiques-of-modernity-in-rationalization-and-ecology/ 
Szrot, Lukas. 2020. "From the Middle: Sites of Culture, Cooperation, and Trust in Risk Society." This View of Life October 26, 2020 https://thisviewoflife.com/ from-the-middle-sites-of-culture-cooperation-andtrust-in-risk-society/

Szrot, Lukas. 2021. Faiths in Green: Religion, Environmental Change, and Environmental Concern in the United States. Lanham, MD: Lexington Books.

Uscinski, Joseph E. 2021. "Clear Thinking about Conspiracy Theories in Troubled Times." Skeptical Inquirer 45(1) https://skepticalinquirer.org/2021/01/ clear-thinking-about-conspiracy-theories-in-troubled-times/?fbclid=IwAR0dElbAriOXmzmep MQpG5tVml7m8P459--m_C3julGYz6z9yFVPwvQiQ

Weber, Max. 1946. “Politics as a Vocation.” In From Max Weber: Essays in Sociology, Translated, Edited, and With an Introduction by H.H. Gerth and C. Wright Mills, pp. 77-128.

Weber, Max. 1946a. "Bureaucracy." In From Max Weber: Essays in Sociology, Translated, Edited, and With an Introduction by H.H. Gerth and C. Wright Mills, pp. 196-244.

Weinberg, Steven. 1992. Dreams of a Final Theory. New York: Pantheon Books.

White, Matthew. 2012. The Great Big Book of Horrible Things: A Definitive Chronicle of History's 100 Worst Atrocities. New York: W.W. Norton \& Company. 